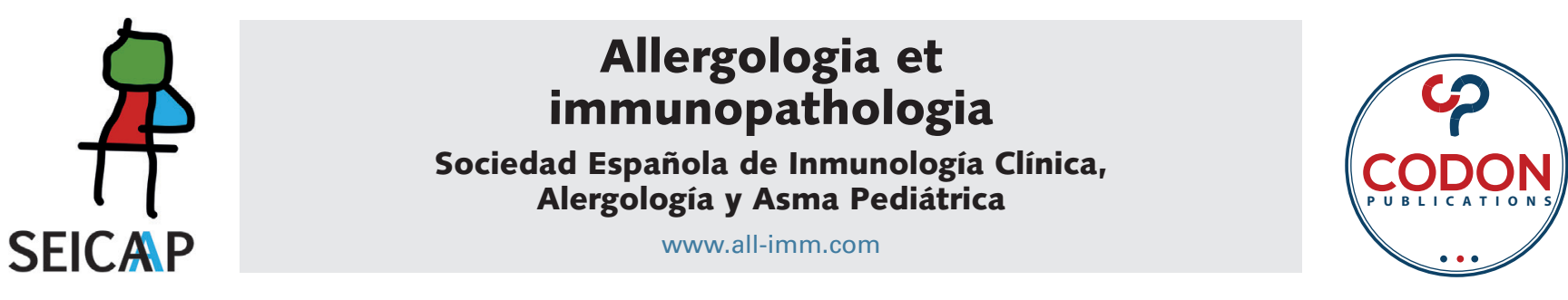

SHORT COMMUNICATION

\title{
Drug reexposure in children with severe mucocutaneous reactions
}

\section{Luis Moral ${ }^{a *}$, Teresa Toral ${ }^{a}$, Ana Gilabert ${ }^{b}$, Ares Sánchez ${ }^{b}$, Juan Francisco Silvestrec, Francisco Manuel Marco ${ }^{d}$}

aPediatric Allergy and Respiratory Unit, Alicante University General Hospital, Alicante Institute for Health and Biomedical Research (ISABIAL), Alicante, Spain

${ }^{b}$ Pediatrics Department, Alicante University General Hospital, Alicante, Spain

'Dermatology Department, Alicante University General Hospital, Alicante Institute for Health and Biomedical Research (ISABIAL), Alicante, Spain

${ }^{d}$ Clinical Immunology Department, Alicante University General Hospital, Alicante Institute for Health and Biomedical Research (ISABIAL), Alicante, Spain

Received 17 March 2021; Accepted 14 December 2021

Available online 1 January 2022

\section{KEYWORDS}

Allergy Workup;

Children;

Drug Provocation

Test;

Nonsteroidal

Anti-inflammatory

Drugs;

Severe Cutaneous

Adverse Reaction

\begin{abstract}
In pediatric patients, severe cutaneous adverse reactions (SCARs) frequently occur in the course of acute illnesses, mostly infections, which are usually treated with antibiotics or analgesics. The drug provocation test (DPT) is contraindicated in such situations, due to the risk of triggering a new severe reaction. As a consequence, lifelong avoidance is recommended. However, causation is uncertain in most cases. The dilemma arises when avoiding the drug is not harmless for the patient. We have attended three patients who were referred to our pediatric allergy unit with a history of SCAR related in time to simultaneous use of paracetamol and ibuprofen. Medical records and images of the patients were reviewed with the assistance of a dermatologist, and alternative diagnoses were considered in both cases. The ALDEN score for implicated drugs was calculated. After considering a high probability of ibuprofen tolerance and obtaining informed consent from the patients, we performed a sequential allergy workup including in vitro tests, skin tests, and finally DPT in two of the patients, confirming ibuprofen tolerance. In conclusion, although generally contraindicated, DPT may be considered for some useful drugs after careful evaluation of the risk-benefit balance, preceded by a sequential study including in vitro and skin tests.
\end{abstract}

๑ 2022 Codon Publications. Published by Codon Publications.

*Corresponding author: Luis Moral, Alicante University General Hospital. C/Pintor Baeza 12, 03010 Alicante, Spain. Email address: Imoralg@gmail.com 


\section{Introduction}

Pediatric allergy units attend a large number of patients with suspected drug hypersensitivity. Most of the suspected reactions are mild, and can be discarded after a drug provocation test (DPT) with the culprit drug. This has a strong positive impact on the quality of life and future healthcare of these patients. Much less frequently, the suspicion of hypersensitivity emerges from the occurrence of a severe cutaneous adverse reaction (SCAR) such as StevensJohnson syndrome (SJS) or toxic epidermal necrolysis (TEN). DPT is contraindicated in these cases due to the risk of triggering a new severe reaction. Therefore, drugs implicated in severe skin or systemic reactions are considered dangerous for the patient, and lifelong avoidance is recommended. ${ }^{1}$ This can be a serious drawback when such drugs are very frequently needed or regarded as the first-choice treatment for the patient, and no equally effective alternatives are available.

In pediatric patients, SCARs frequently occur in the course of acute illnesses, mostly infections, which are usually treated with antibiotics or analgesics, making it difficult to discern whether the reaction was related to the administered drugs or the ongoing disease. ${ }^{2}$ Paracetamol and ibuprofen are the two most commonly used analgesic and antipyretic drugs in pediatrics. When both are involved in SCAR, the dilemma of recommending their lifelong avoidance arises, with the need to resort to other second-line drugs for the symptomatic treatment of fever or pain, with the added issue of possible cross-reactivity with other nonsteroidal anti-inflammatory drugs. ${ }^{3}$ We attended three patients who were referred to our pediatric allergy unit with a history of SCAR related in time to paracetamol and ibuprofen use. These patients and their relatives signed the consent for review and anonymized publication of their clinical data.

\section{Case Reports}

The main data of these three patients are shown in Table 1. All three of them had received metamizol during hospitalization, with no observed adverse effects. Medical records and images of the patients were reviewed in our pediatric allergy unit with the assistance of a dermatologist, and alternative diagnoses were considered in two of the cases (Table 1). The ALDEN score, an algorithm specifically designed to evaluate the causality of drugs involved in SJS and TEN, ${ }^{4}$ was calculated (Table 1 ). After this evaluation, it was considered that these patients would have a high probability of tolerating, at least, ibuprofen. Given that the performance of DPT, the definitive test to verify tolerance, is considered contraindicated in patients with SCAR in the main international clinical guidelines, a formal consultation with the Clinical Ethics Committee of the Alicante University General Hospital was made. The committee raised no objections to request appropriate informed consent to carry out a sequential allergy workup including in vitro tests, skin tests and, finally, DPT. The families consented, and all tests were performed between 3 and 12 months after the index reaction (Table 1). The lymphocyte transformation test was performed with increasing concentrations of paracetamol and ibuprofen, and the stimulation index was calculated. The patch tests were performed with $10 \%$ paracetamol and $10 \%$ ibuprofen in petrolatum. The patches were applied for $48 \mathrm{~h}$ to the upper back and read at the time of patch removal and again $48 \mathrm{~h}$ later ( $96 \mathrm{~h}$ from patch placement). The prick test $(5 \mathrm{mg} / \mathrm{ml})$ and intradermal test $(0.1 \mathrm{mg} / \mathrm{ml})$ with ibuprofen were followed by immediate (15 min) and delayed (48-72 h) readings. After obtaining negative results with these tests, Patient 1 tolerated DPT with increasing single doses of ibuprofen, with weekly administration and observation intervals (5 mg, $20 \mathrm{mg}, 100 \mathrm{mg}$, and $400 \mathrm{mg})$. After that, a course of $400 \mathrm{mg}$ of ibuprofen was administered every $8 \mathrm{~h}$ for 2 days (6 doses in total), which was also tolerated. In Patient 3, a similar DPT was performed, though some doses had to be repeated due to mild oral discomfort (small canker sores, mild lip edema), which the patient had already suffered occasionally before DPT and did not reappear, with a final tolerated dose of $300 \mathrm{mg}$ repeated at $12 \mathrm{~h}$ ( 2 doses). Patients 1 and 3 have subsequently taken ibuprofen as a symptomatic treatment, with good tolerance. In Patient 2, the decision was made to not perform DPT due to the presence of severe corneal sequelae with visual impairment.

\section{Discussion}

Children with a history of SCAR related in time to drug administration are usually advised to avoid the suspected drug. However, causation is uncertain in most cases. The dilemma arises when avoiding the drug is not harmless for the patient. Firstly, it is important to try verify the reported diagnosis. The diagnosis of SJS and TEN may overlap with other disorders such as erythema multiforme major or mucositis associated with Mycoplasma pneumoniae infection, making it very difficult to confirm the implication of drugs in these episodes. ${ }^{5}$ Secondly, the ALDEN score may help to determine the probability of causation for any implicated drug. ${ }^{4}$ Although DPT is contraindicated due to the risk of recurrence of a severe reaction, it may be contemplated when causation is considered unlikely, and drug avoidance implies disadvantages or risks for the patient after carefully considering the risk-benefit ratio. DPT should be preceded by a sequential study, including in vitro tests and skin tests, after obtaining informed consent from the patient and family. ${ }^{6,7}$ A similar approach to that described above has been proposed and carried out in patients with DRESS syndrome. ${ }^{8}$ There are few reported cases of intentional or unintentional reexposure to the drug involved in SCAR, $7,9-11$ and even fewer cases in pediatric patients, ${ }^{12-14}$ mostly with satisfactory results. A recent study has shown the ability of high-dose intravenous corticosteroids to reverse the recurrence of symptoms during DPT in patients with SJS and DRESS syndrome, potentially improving the safety of drug rechallenge protocols in these patients. ${ }^{15}$

\section{Conclusion}

Although generally contraindicated, DPT may be considered for some useful drugs weakly implicated in SCAR (based on 


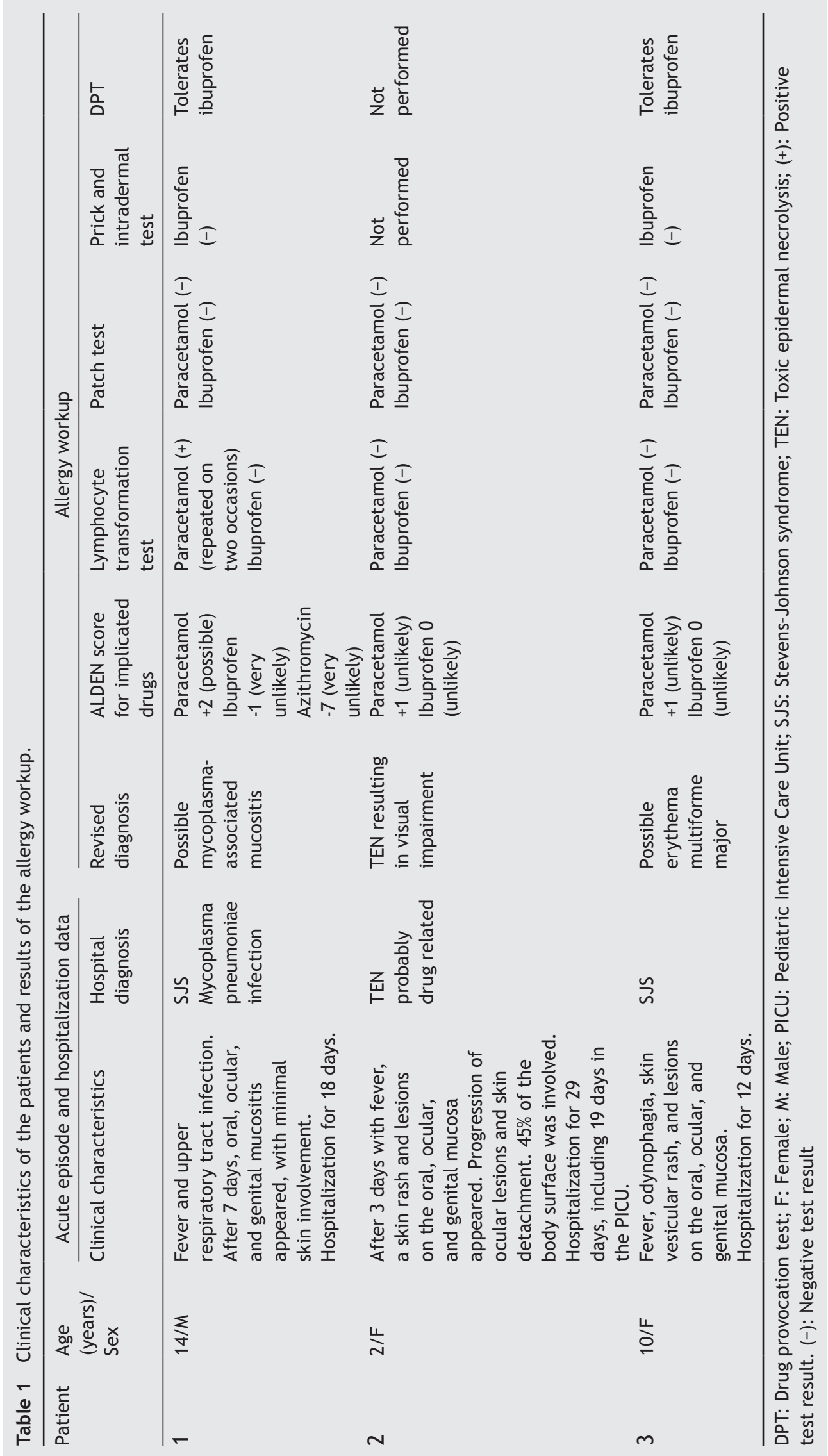


the revised diagnosis and/or ALDEN score), after adequate evaluation of the risk-benefit balance and the obtainment of informed consent from the patient, preceded by $a$ sequential study including in vitro and skin tests.

\section{Conflict of Interest and Funding}

The authors declare that they have no potential conflicts of interest with respect to research, authorship, and/or publication of this article.

This research received no specific grants from funding agencies in the public, commercial, or not-for-profit sectors. The authors declare that they have no conflicts of interest, financial relationships, or funding sources relevant to this article.

\section{References}

1. Gomes ER, Brockow K, Kuyucu S, Saretta F, Mori F, BlancaLopez N, et al. Drug hypersensitivity in children: Report from the pediatric task force of the EAACI Drug Allergy Interest Group. Allergy 2016;71(2):149-61. https://doi.org/10.1111/ all.12774

2. Liccioli G, Mori F, Parronchi P, Capone M, Fili L, Barni S, et al. Aetiopathogenesis of severe cutaneous adverse reactions (SCARs) in children: A 9-year experience in a tertiary care paediatric hospital setting. Clin Exp Allergy. 2020;50(1):61-73. https://doi.org/10.1111/cea.13513

3. Abreu S, Castelblanco-Arango IY, Gómez-Pineda PA, Cardona R. Drug provocation tests to identify analgesic alternatives for an infant with Stevens-Johnson syndrome caused by ibuprofen-acetaminophen. Rev Alerg Mex. 2020;67(2):18995. https://doi.org/10.29262/ram.v67i2.712

4. Sassolas B, Haddad C, Mockenhaupt M, Dunant A, Liss $Y$, Bork $\mathrm{K}$, et al. ALDEN, an algorithm for assessment of drug causality in Stevens-Johnson syndrome and toxic epidermal necrolysis: Comparison with case-control analysis. Clin Pharmacol Ther. 2010;88(1):60-8. https://doi.org/10.1038/ clpt.2009.252

5. Liccioli G, Filippeschi C, Giovannini M, Capone M, Oranges T, Barni S, et al. Mycoplasma pneumoniae-associated mucocutaneous disease in children: A case series with allergy workup in a tertiary care paediatric hospital. Clin Exp Allergy. 2021;51(5):740-4. https://doi.org/10.1111/cea.13861

6. Ardern-Jones MR, Mockenhaupt M. Making a diagnosis in severe cutaneous drug hypersensitivity reactions. Curr Opin Allergy Clin Immunol. 2019;19(4):283-93. https://doi. org/10.1097/aci.0000000000000546

7. Lehloenya RJ, Peter JG, Copaescu A, Trubiano JA, Phillips EJ. Delabeling delayed drug hypersensitivity: How far can you safely go? J Allergy Clin Immunol Pract. 2020;8(9):2878-95.e6. https://doi.org/10.1016/j.jaip.2020.07.005

8. Desroche T, Poreaux C, Waton J, Schmutz JL, Menetre S, Barbaud A. Can we allow a further intake of drugs poorly suspected as responsible in drug reaction with eosinophilia and systemic symptoms (DRESS)? A study of practice. Clin Exp Allergy. 2019;49(6):924-8. https://doi.org/10.1111/cea.13380

9. Katoh N, Kagawa K, Yasuno H. Piroxicam induced StevensJohnson syndrome. J Dermatol. 1995;22(9):677-80. https:// doi.org/10.1111/j.1346-8138.1995.tb03897.x

10. Kawada M, Nobeyama Y, Goto Y, Nakama K, Yamazaki N, Asahina A. Absence of toxic epidermal necrolysis recurrence with pembrolizumab re-challenge in a patient with a positive lymphocyte transformation test. J Dermatol. 2020;47(12):e424-5. https://doi.org/10.1111/1346-8138.15572

11. Jin HJ, Kang DY, Nam YH, Ye YM, Koh Y-I, Hur G-Y, et al. Severe cutaneous adverse reactions to anti-tuberculosis drugs in Korean patients. Allergy Asthma Immunol Res. 2021;13(2):24555. https://doi.org/10.4168/aair.2021.13.2.245

12. Halevi A, Ben-Amitai D, Zion Garty B. Toxic epidermal necrolysis associated with acetaminophen ingestion. Ann Pharmacother. 2000;34(1):32-4. https://doi.org/10.1345/ aph.19064

13. Trujillo C, Gago C, Ramos S. Stevens-Jonhson syndrome after acetaminophen ingestion, confirmed by challenge test in an eleven-year-old patient. Allergol Immunopathol (Madr). 2010;38(2):99-100. https://doi.org/10.1016/j.aller.2009.06.009

14. Lezmi G, Alrowaishdi F, Bados-Albiero A, Scheinmann P, de Blic J, Ponvert C. Non-immediate-reading skin tests and prolonged challenges in non-immediate hypersensitivity to beta-lactams in children. Pediatr Allergy Immunol. 2018;29(1):84-9. https://doi.org/10.1111/pai.12826

15. Lehloenya RJ, Isaacs T, Nyika T, Dhana A, Knight L, Veenstra S, et al. Early high-dose intravenous corticosteroids rapidly arrest Stevens Johnson syndrome and drug reaction with eosinophilia and systemic symptoms recurrence on drug re-exposure. J Allergy Clin Immunol Pract. 2021;9(1):582-4.e1. https://doi.org/10.1016/j.jaip.2020.08.012 